\title{
Definição de Experiência Fora do Corpo a partir de Relatos de Experiências Similares
}

\author{
Gabriel Teixeira de Medeiros ${ }^{1, *}$ (ID \& Fernando de Almeida Silveira ${ }^{2}$ \\ ${ }^{1}$ Universidade de São Paulo, São Paulo, SP, Brasil \\ ${ }^{2}$ Universidade Federal de São Paulo, São Paulo, SP, Brasil
}

\begin{abstract}
RESUMO - Diversas abordagens foram utilizadas para entender as Experiências Fora do Corpo (EFC), contudo, não há consenso sobre sua etiologia, definição e características constitutivas. Este artigo buscou comparar definições de EFC com experiências semelhantes, não consideradas como EFC por seus protagonistas. Treze participantes narraram experiências durante entrevistas semiestruturadas, as quais foram submetidas à análise de conteúdo. Três participantes descreveram experiências que se enquadram a três categorias de EFCs distintas. O não reconhecimento da experiência como EFC esteve relacionado à atribuição de causalidade e crenças paranormais e religiosas. Tais dados sugerem a necessidade de separação entre a definição da experiência e sua atribuição de causalidade, bem como uma abordagem multietiológica e fenomenológica no estudo de EFC.
\end{abstract}

PALAVRAS-CHAVE: experiência fora do corpo, psicologia anomalística, experiências anômalas, fenomenologia, Merleau-Ponty

\section{Out-of-Body Experience Definition by Reports about Similar Experiences}

\begin{abstract}
Several approaches have been used to understand out-of-body experiences (OBE); however, there is no consensus about its etiology, definition and constitutive characteristics. This study aimed to compare the definition of OBE with experiences similar to OBE but not classified as such by its experiencers. Thirteen respondents reported their experiences in a semistructured interview, which was analyzed using content analysis. Three of them described experiences that fit into three different categories of OBEs. Failure to recognize the experience as OBE was related to causal attributions and paranormal and religious beliefs. These data suggest the need for a separation of the definition of experience from its causal attribution as well as a multi-etiologic and phenomenological approach in the study of OBE.
\end{abstract}

KEYWORDS: out-of-body experience, anomalistic psychology, anomalous experiences, phenomenology, Merleau-Ponty

Gabbard e Twemlow (1984) sugerem uma prevalência mundial de Experiências Fora do Corpo (EFC) entre 10 e $25 \%$. No entanto, estudos com diferentes populações divergem amplamente nas porcentagens encontradas, que variam entre $8 \%$ (Haraldsson, Gudmundsdottir, Ragnarsson, Loftsson, \& Jonsson, 1977) e 50\% (Kohr, 1980). Diversos estudos apontaram para prevalências entre esses extremos (Blackmore, 1982, 1987; Green, 1966; Hart, 1954; Irwin, 1985; Palmer, 1979; Tart, 1972; ), entre eles, um estudo com universitários brasileiros, em que $31 \%$ dos respondentes afirmaram ter vivenciado uma EFC (Zangari \& Machado,
2001, p. 7-8). A prevalência de EFC é maior em grupos com interesse por estudos espirituais ou parapsicológicos, como na Association for Research and Enlightenment (Kohr, 1980) e em conferências de Parapsicologia (Blackmore, 1986), com $37 \%$ de prevalência entre os participantes, apontando para a importância do interesse no tema e da crença em tais fenômenos para a existência da experiência.

Contudo, com descrições de EFCs muito diversas e abordagens que se estendem da investigação da possibilidade de saída do espírito do corpo físico (Bozzano, 1911; Myers, 1903 ) até estudos que entendem a EFC como alucinação

*E-mail: gabriel_tmedeiros@yahoo.com

- Submetido: 24/06/2016; Aceito: 04/08/2017. 
causada por distúrbios na Junção Têmporo-Parietal (Blanke, Landis, Spinelli, \& Seeck, 2004) ou ilusões do próprio corpo (Ehrsson, 2007), as definições de EFC parecem múltiplas e com poucos pontos consensuais. Desse modo, apresentaremos, inicialmente, um panorama dos estudos de EFC, a fim de refletir sobre a definição, nomeação e reconhecimento destas experiências.

O estudo sobre EFC consolidou-se no final do século XIX. O conceito de espírito ou corpo sutil como objeto que se desloca do corpo físico foi utilizado como explicação de tais fenômenos por pesquisadores como Ernesto Bozzano (1911) e Frederic Myers (1903). Em contraponto às ideias de espírito ou corpo sutil, encontra-se outros pesquisadores e membros da Society for Psychical Research, como Edmund Gurney, Podmore, Mrs. Sidgwick e Charles Richet, que consideraram tais fenômenos como alucinações ou meros sonhos. Hyslop (citado por Alvarado, 1989), por sua vez, aceitou o componente extrassensório da experiência, mas atribuiu a sensação de EFC à tendência da mente subconsciente para dramatizar imagens de localidade que dão a impressão de que o evento se dava em uma diferente localização física. Charles T. Tart $(1968,1976)$ inaugura uma era de estudos mais sofisticados, a partir do uso de eletroencefalograma. Ele buscou analisar a atividade elétrica do cérebro durante EFC de sujeitos que alegavam ter percepções extrassensoriais (PES) enquanto vivenciavam EFC. Contudo, embora estudos como o de Tart (1968) tenham apontado alguns comportamentos na atividade cerebral, não característicos do sono normal e seus estágios, nenhum dado corroborou a separação entre mente-cérebro proposta por Osis (1973) como verificação necessária à EFC (Twemlow, Gabbard, \& Jones, 1982, p. 450).

Em uma série de quatro estudos, Palmer (Palmer, 1979; Palmer \& Liberman, 1975, 1976; Palmer \& Vassar, 1974) tentou induzir EFCs em voluntários por meio de técnicas de relaxamento e privação sensorial. Em seguida, comparou os escores de PES entre os que relataram EFC e os que afirmaram falhar em induzi-la, não havendo diferença significativa entre os escores. Todavia, Alvarado (2000) aponta para uma correlação positiva de EFC com alegações de PES espontâneas e com uma variedade de alegações parapsicológicas, como experiências místicas e observação de aparições e/ou auras.

Outros estudos buscaram entender a EFC por modelos cerebrais (Blanke, Ortigue, Landis, \& Seeck, 2002; De Ridder, Van Laere, Dupon, Menovsky, \& Van de Heyning, 2007; Neppe, 1989; Persinger, 1989;), apontando para diferentes pontos de estimulação cerebral e/ou danos e distúrbios cerebrais que induziriam à EFC. Entretanto, Neppe $(1989,2011)$ destaca a diferença fenomenológica e etiológica entre EFCs induzidas por estimulação cerebral e as espontâneas, bem como considera a possibilidade de existência de EFCs não relacionadas a danos cerebrais ou patologias.

Os modelos psicológicos também consideram a existência de EFCs patológicas e não patológicas, com destaque aos modelos de Palmer (1978), Blackmore (1984b) e Irwin (1985). Susan Blackmore (1984b) sugere que a EFC é um modelo da realidade criada pelo organismo, utilizando recursos cognitivos quando os modelos dependentes da entrada sensorial são interrompidos, de modo a retomar o controle sobre o meio externo. Segundo ela, características como a interrupção do input com o mundo, a habilidade de alterar o ponto de visão quando desejado, a capacidade de absorção em experiências internas e a construção de um modelo de mundo alternativo e viável por meio de suas memórias poderiam gerar tais experiências (Blackmore, 1986, p. 219). A autora também sugere uma maior habilidade relacionada à imaginação e criação de figuras mentais (1986) em EFCs espontâneas, criação de uma imagem do mundo aparentemente real. No entanto, Blackmore (1984a) confere maior importância à habilidade de tornar-se convicto da realidade do mundo imaginado do que à vivacidade do cenário imaginado.

A despeito das discussões sobre a natureza da EFC e sua relação com PES e patologias, a EFC insere-se na categoria de experiências denominadas anômalas (Cardeña, Lynn, \& Krippner, 2000; Holt, Simmonds-Moore, Luke, \& French, 2012), pois estas são compreendidas como referentes às vivências humanas - enquanto fato psíquico - que não podem ser explicadas pelo paradigma científico vigente (Cardeña et al., 2000). Estas ainda coadunam com o termo anomalia, proposto por Thomas Kuhn (1962), o qual não implica, necessariamente, uma patologia (Machado, 2010). Essas experiências anômalas (EAs) figuram como objeto de dois campos correlatos, a Parapsicologia e a Psicologia Anomalística. Enquanto a Parapsicologia ocupa-se da realidade ontológica dos fenômenos psi, a Psicologia Anomalística foca no sujeito das experiências e nos aspectos psicológicos envolvidos ou resultantes das experiências (Machado, 2010, p. 465), sem atribuir às experiências qualidades intrínsecas e independentes de seu contexto histórico-social, uma vez que considera que as noções de normal e "paranormal" são convencionadas a partir de uma dada cultura (Maraldi, Zangari, \& Machado, 2011, p. 396).

\section{O PROBLEMA DA DEFINIÇÃO}

$\mathrm{O}$ fenômeno de EFC refere-se a "uma experiência na qual a pessoa parece perceber o mundo a partir de um local fora de seu corpo físico" (Blackmore, 1982, p. 1). A EFC pode ser desencadeada por meio do sono, apesar de Gabbard e Twemlow (1984) sugerirem que tal sensação é percebida de modo mais vívido que o sonho (p. 31). Por outro lado, 
também pode ocorrer durante atividades físicas (Alvarado, 2016), meditação profunda, experiências de quase morte (EQM), traumas, estimulação cerebral (Blanke \& Arzy, 2005), ilusões de óptica controladas (Ehrsson, 2007), indução hipnótica (Tressoldi et al., 2015), entre outras. Embora se considerem diferentes causas para a EFC, a única característica consensual entre as definições desta é a sensação de localização da percepção própria em outro local que não o corpo físico (Palmer \& Vassar, 1974).

Estudos com uso de questionário encontraram outras características comuns a diversas EFCs, como: reincidência da experiência; indução voluntária; autoscopia; aparição de outras pessoas durante a EFC (Palmer, 1979); visão em $360^{\circ}$; presença de objetos brilhantes, transparentes ou com auras; corpo "sem volume ou espaço"; perda da tanatofobia; melhora na saúde mental após EFC (Osis, 1979); duplicação de corpos; sensação de energia ou vibração; desejo de ter outra EFC e persistências dos benefícios obtidos com a experiência (Twemlow et al., 1982); relação com outras experiências psíquicas ou relacionadas, como experiências místicas, sonhos lúcidos e lembrança mais frequente de sonhos (Blackmore, 1984a). No entanto, essas características não estão presentes em todas as EFCs e não são exclusivas destas experiências, o que pode fazer com que experiências similares sejam confundidas com EFCs, como em alguns casos de sonhos lúcidos (Laberge, Levitan, Brylowski, \& Dement, 1988; Levitan, Laberge, DeGarcia, \& Zimbardo, 1999). O sonho lúcido é um tipo específico de sonho em que se tem consciência de estar sonhando durante o sonho (Laberge, Nagel, Dement, \& Zarcone, 1981; Mota-Rolim \& Araujo, 2013), podendo ou não haver controle sobre o conteúdo onírico (Mota-Rolim et al., 2013).

Os estudos com uso de questionários foram amplamente utilizados. Contudo, é justamente em seu uso que aparecem os maiores entraves relacionados à dificuldade de definição da EFC. Diversos questionários utilizaram apenas uma pergunta para definir EFC, baseada na questão de Palmer (1979): "você já (...) sentiu como se se deslocasse 'para fora' ou 'para longe' de seu corpo (...) sua consciência estava em algum lugar diferente de seu corpo (...)" (p. 231). No entanto, Alvarado (2000) alerta que o uso de uma única questão dicotômica pode superestimar a prevalência do fenômeno e aponta a necessidade da inclusão da exteriorização do lócus de percepção, a fim de evitar ambiguidades (p. 184), como as existentes entre sonho, sonho lúcido e EFC (Sá \& Mota-Rolim, 2015). O problema da utilização de uma única questão também pode impedir que respostas positivas sejam observadas quando, durante a experiência, há duas localidades para a consciência (dentro e fora do corpo) ou em experiências em que, embora ainda dentro do corpo, a pessoa sinta-se parcialmente fora ou desligada de seu corpo, como no caso das experiências descritas por Whiteman (1980, 2006).

Por fim, é importante considerar que a EFC, quando estudada por meio de questionários ou entrevistas, é passível de análise apenas a partir da interpretação de seu acontecimento por parte daqueles que alegam vivenciá-la. Assim, a diferenciação entre EFC e outras experiências similares é sempre dependente, em certo grau, do próprio sujeito que a vive, de modo que o problema da definição permanece. Entretanto, Neppe (2011) propõe o entendimento da EFC a partir de uma multiplicidade de fenômenos distintos, mas com mesmo nome. Entre estes, Neppe inclui a categoria de experiências paranormais subjetivas, que mesmo quando ontologicamente negadas, devem ser observadas a partir dos sentidos e efeitos causados nos sujeitos que as vivenciam enquanto fatos psíquicos. Portanto, no intuito de analisar fenomenologicamente tais experiências, a questão não é a veracidade da percepção, mas ao contrário, "o mundo é aquilo que nós percebemos" (Merleau-Ponty, 2006, p.13-14), pois "quando sonho que voo ou caio, todo o sentido desse sonho está contido nesse voo ou nessa queda, se eu não os reduzo à sua aparência física no mundo da vigília, e se os considero com todas as suas implicações existências" (Merleau-Ponty, 2006, p. 383).

Desse modo, a percepção é o ato que cria o sentido que une os dados apreendidos, de modo que para a fenomenologia não se trata de descobrir o sentido escondido nas experiências, mas, mediante a percepção, fazer com que tenham sentido (Veríssimo \& Furlan, 2007). Isso porque é a intencionalidade da consciência que significa a ação humana, sem a qual não poderia se falar de objeto ou de essência (Sadala, 2004). Assim, entendemos que o estudo da EFC deva se focar não apenas na definição estrita da EFC perante a ciência, mas na subjetividade de sua experiência, a qual produz consequências variadas e que concorrem para o entendimento e reconhecimento de dada experiência enquanto EFC por parte de quem a vive.

\section{Objetivos}

O objetivo deste artigo é observar e descrever as similaridades e diferenças entre as características e possíveis definições de EFC apresentadas acima e experiências consideradas similares e vividas por pessoas que alegam nunca terem vivenciado uma EFC. Deseja-se investigar se há experiências consideradas apenas similares à EFC, mas que poderiam se enquadrar como EFC, bem como explorar os sentidos dados a experiências narradas e os motivos para não as reconhecer como EFC, a fim de contribuir para um maior entendimento sobre a definição de EFC e questões correlatas, como o reconhecimento da experiência enquanto EFC e atribuição de causalidade e a multiplicidade das EFCs. 


\section{METODOLOGIA}

Utilizamos uma abordagem qualitativa por meio de entrevistas semiestruturadas. O critério de inclusão foi o fato de o entrevistado afirmar, no momento em que foi convidado a participar da entrevista, nunca ter vivenciado uma EFC, de modo que todos aqueles que acreditam ter vivido tal experiência foram excluídos. O número total de participantes não foi decidido a priori, mas determinado ao longo da coleta de dados, por meio do critério de saturação (Patton, 1990), baseando-se nas variações de sonhos consideradas consistentes preditores de EFC: sonhos lúcidos, sonhos de voo (quando a pessoa sonha estar voando) e sonhos vívidos e muito reais (Alvarado, 2000). Optamos, também, por incluir a autoscopia ao critério de saturação por sua estreita relação com EFCs. Assim, uma análise preliminar dos dados buscou averiguar o momento em que novas entrevistas pouco acrescentavam de informações substanciais referentes a tais experiências. Quando tal ponto foi atingido, consideramos que o ponto de saturação havia sido alcançado, com um total de treze participantes.

Os participantes foram acessados por meio de chain sampling, método que consiste na indicação de sujeitos por meio de entrevistados anteriores do estudo, até contemplar o critério de saturação (Patton, 1990). O ponto inicial foram estudantes da UNIFESP - Campus Baixada Santista.

O estudo foi aprovado pelo Comitê de Ética em Pesquisa - Plataforma Brasil em novembro/2012, sob o parecer número 142.729, de 01 de novembro de 2012. Todos foram entrevistados de forma individual e sigilosa, após leitura e concordância com o Termo de Consentimento Livre e Esclarecido. As entrevistas ocorreram no laboratório de pesquisa social, foram gravadas após autorização dos entrevistados e, posteriormente, transcritas, visando à análise.

Antes da entrevista, cada participante respondeu o Questionário de Prevalência e Relevância de Psi (Q-PRP, construído e validado por Machado, 2009), que possibilitou a coleta de dados demográficos e sobre as EAs vivenciadas pelos respondentes. Dentre as questões do Q-PRP que avaliam as EAs vividas pelos respondentes, inclui-se a questão referente à EFC proposta por Palmer (1979) e apresentada na introdução deste estudo. Porém, ressalta-se que responder afirmativamente a essa questão não se configurava como critério de exclusão, uma vez que, os participantes confirmavam ter vivenciado uma exteriorização do lócus de percepção, mas não consideravam esta como uma EFC.
A entrevista se baseou na descrição da experiência mais semelhante à EFC vivida pelo sujeito - suas percepções, sensações, desdobramentos da experiência em sua vida, os sentidos dados a esta e como ela foi reconhecida, bem como questões referentes ao entendimento corpo-alma e crenças em PES e EFC, a fim de melhor entender o sentido dado à experiência.

Parte-se do entendimento de que fenômeno e sentidos se encontram imbricados no mesmo ato, pois a despeito das propriedades do próprio objeto, o fenômeno existe apenas "em função daquele que o observa e, nessa visada, lhe atribui sentido" (Freitas, Araújo, Franca, Pereira, \& Martins, 2012, p. 144-154), ou seja, na concepção de percepção enquanto uma interpretação, "a sensação, que serviu de ponto de partida, está definitivamente ultrapassada, qualquer consciência perceptiva já estando para além dela" (Merleau-Ponty, 2006, p.66). Assim, não buscamos definir as experiências narradas (ou seja, determinar se são ou não $\mathrm{EFCs}$ ), mas apenas identificar semelhanças com as definições de EFC, considerando que mesmo uma experiência que poderia ser enquadrada como EFC deve apresentar esta interpretação por parte daquele que a vivencia, para sê-la.

Utilizamos a análise de conteúdo, que permite emergir "núcleos de sentido" extraídos dos relatos dos participantes por meio de orações expressivas de um discurso em relação ao tema investigado e sua relação com os demais entrevistados. As entrevistas foram analisadas, inicialmente, para descrever o fenômeno vivido por cada entrevistado; para, em seguida, relevar e listar todas as categorias encontradas (Moustakas, 1994).

Essas categorias nortearam a construção de duas descrições, uma sobre o que fora vivenciado e como ocorreu a experiência (as características desta, circunstância em que ocorreu etc.) e outra sobre as interpretações e sentidos dados à experiência (como, por exemplo, os motivos para não considerá-la uma EFC, a forma como nomeavam a experiência, o papel da experiência em suas vidas, entre outros) (Creswell, 2012). Essa técnica permitiu que as falas de participantes fossem agrupadas a partir da definição dos núcleos de sentido emergentes dos dados, tendo a fenomenologia merleau-pontyana como referência de interpretação. Por fim, as experiências foram divididas em quatro grupos, a partir de suas características e em relação à sua proximidade com a definição de EFC.

\section{RESULTADOS}

A ordem cronológica das entrevistas, por meio de chain sampling, e os dados sociodemográficos dos entrevistados são apresentados na Tabela 1. A média de idade dos participantes foi de 31,53 anos $(D P=14,9423)$. 
Tabela 1

Dados sociodemográficos

\begin{tabular}{|c|c|c|c|c|c|c|c|}
\hline Entrevista & Nome fictício & Sexo & Idade & Naturalidade & Escolaridade & Crença Religiosa & Quão religioso se considera \\
\hline 01 & Raul & M & 29 & Guarujá/SP & $\begin{array}{l}\text { Superior } \\
\text { Completo }\end{array}$ & Ateu & Nem um pouco \\
\hline 02 & Karen & $\mathrm{F}$ & 34 & $\begin{array}{c}\text { Poços de } \\
\text { Caldas/MG }\end{array}$ & Pós-graduação & Católica & Moderadamente \\
\hline 03 & Renato & M & 25 & Jabuticabal/SP & Pós-graduação & Católico & Moderadamente \\
\hline 04 & Diego & M & 25 & Bebedouro/SP & $\begin{array}{l}\text { Superior } \\
\text { Incompleto }\end{array}$ & Ateu & Nem um pouco \\
\hline 05 & Lurdes & $\mathrm{F}$ & 41 & São Vicente/SP & Pós-graduação & $\begin{array}{l}\text { Católica e Espírita } \\
\text { "simpatizante" }\end{array}$ & Moderadamente \\
\hline 06 & Bernardo & M & 21 & São Paulo/SP & $\begin{array}{l}\text { Superior } \\
\text { Incompleto }\end{array}$ & Agnóstico & Pouco \\
\hline 07 & Mariana & $\mathrm{F}$ & 27 & $\begin{array}{c}\text { São Caetano do } \\
\text { Sul/SP }\end{array}$ & Pós-graduação & Espírita & Pouco \\
\hline 08 & Augusto & M & 40 & Santos/SP & Pós-graduação & Agnóstico & Nem um pouco \\
\hline 09 & Ana & $\mathrm{F}$ & 24 & São Vicente/SP & $\begin{array}{l}\text { Superior } \\
\text { Incompleto }\end{array}$ & Agnóstica & Pouco \\
\hline 10 & Vanessa & $\mathrm{F}$ & 22 & Registro/SP & $\begin{array}{l}\text { Superior } \\
\text { Incompleto }\end{array}$ & $\begin{array}{l}\text { Sem filiação religiosa, } \\
\text { mas crê em Deus }\end{array}$ & Pouco \\
\hline 11 & Alberto & M & 76 & Recife/PE & Médio Completo & Espírita & Moderadamente \\
\hline 12 & Priscila & $\mathrm{F}$ & 26 & São Paulo/SP & Pós-graduação & Católica & Pouco \\
\hline 13 & José & M & 20 & $\begin{array}{l}\text { São Bernardo } \\
\text { do Campo/SP }\end{array}$ & $\begin{array}{c}\text { Superior } \\
\text { Incompleto }\end{array}$ & Umbandista e Agnóstico & Pouco \\
\hline
\end{tabular}

As experiências narradas foram divididas em quatro grupos: I- Quasi-EFC (experiências que se enquadram em critérios de EFC e poderiam ser entendidas como tal); II- Sonhos lúcidos ou muito reais; III- Experiências religiosas; IV- Entrevistados que não recordaram ou não souberam identificar nenhuma experiência específica que se assemelhasse à EFC (Quadro 1).

\section{Grupo I - Quasi-EFC}

Dos 13 entrevistados, três narraram experiências que, embora não entendessem como EFC, encaixam-se em definições de EFC, de acordo com a literatura específica da área. Diego (entrevista \#04) afirma que sentiu sair do próprio corpo em uma ocasião. Ele relata que fazia exercícios com esse objetivo e era muito interessado em assuntos místicos, mas que, à época da experiência, já havia se desinteressado com o tema, em função da graduação em curso. A vivência ocorreu à noite, durante o estado hipnagógico, "aquele milésimo de segundo antes de você começar a dormir mesmo" (Diego), em que há o sentimento de deslizar por dentro de seu próprio corpo e sair pela cabeça:

É como se eu saísse, visse as coisas de fora; eu só sabia que eu tava saindo pela visão que eu tava tendo, de que eu tava subindo e como se eu mergulhasse pra frente, na televisão. Foi a experiência mais próxima que eu tive disso. E eu acordei assustado, como se tivesse tomando um tranco. E voltado assim... não sei... (Diego)
Ana (entrevista \#09) relata que, durante sua prática de ioga, em diversas ocasiões, sentiu seu corpo "diferente". Mesmo parada, sentia como se seu corpo se mexesse. Ela afirma que, certas vezes, chegava a sentir outro corpo (um duplo de seu corpo físico) sentado sobre seus ombros. Essa experiência é similar às experiências separativas dentro e fora do corpo físico descritas por Whiteman (2006). Contudo, Ana considera que tal experiência se situou majoritariamente no campo imaginativo: " $E$, visualmente eu imagino que o meu corpo seja dois corpos. Mas eu acho que é uma coisa mais imaginável, não tô vendo... É, não sei, eu não tô vendo nada..." (Ana).

Por fim, Raul (entrevista \#01) também descreve uma experiência similar às experiências separativas ainda dentro do corpo. Ele também afirma, como Diego, ter feito exercícios para induzir uma $\mathrm{EFC}$ e diz que estudava ocultismo e esoterismo, mas que, quando a experiência narrada ocorreu (em 2003), havia abandonado tais estudos há dois anos. Sua experiência se iniciou como um sonho lúcido. Raul estava em um metrô que diz parecer um metrô da Europa ou Estados Unidos e viu uma mulher vir em sua direção. Quando tentou virar sua cabeça para ver uma placa que não conseguira ler, Raul afirma que houve um desencontro entre a imagem do sonho e sua intenção, como “uma briga, realmente. A câmera... é como se fosse... a câmera ficasse brigando. Né?". 
Quadro 1

Descrição das experiências

\begin{tabular}{|c|c|c|c|c|}
\hline $\begin{array}{l}\text { Nome } \\
\text { Fictício }\end{array}$ & Grupo & $\begin{array}{l}\text { Categorias encontradas nas } \\
\text { experiências narradas }\end{array}$ & $\begin{array}{c}\text { Experiências anômalas } \\
\text { assinaladas no questionário }\end{array}$ & Possíveis causas \\
\hline Diego & \multirow{3}{*}{ I- Quasi-EFC } & $\begin{array}{l}\text { Sensação de exteriorização } \\
\text { do lócus de percepção }\end{array}$ & EFC & Alucinação \\
\hline Ana & & $\begin{array}{l}\text { Sensação de flutuação; Presença } \\
\text { de um duplo ao corpo físico } \\
\text { (acima do corpo físico) }\end{array}$ & $\begin{array}{l}\text { Intuição; Contato não natural' } \\
\text { EFC }\end{array}$ & $\begin{array}{l}\text { Intuição; Coincidência; } \\
\text { Ação de seu espírito }\end{array}$ \\
\hline Raul & & $\begin{array}{l}\text { Sonho lúcido; Hipersensibilidade; } \\
\text { Presença de um duplo ao corpo físico } \\
\text { (ainda no corpo físico) }\end{array}$ & Contato não natural $^{1}$ & Atividade cerebral \\
\hline Vanessa & \multirow{4}{*}{$\begin{array}{l}\text { II- Sonhos } \\
\text { Lúcidos ou } \\
\text { muito reais }\end{array}$} & $\begin{array}{l}\text { Sonho lúcido; Paralisia } \\
\text { do sono; Autoscopia }\end{array}$ & Sonho premonitório & Não soube responder \\
\hline Augusto & & Sonho lúcido; Sonho de voo & Contato não natural $^{1} ; \mathrm{EFC}$ & Poder da mente \\
\hline Karen & & Sonho muito real & Casa assombrada & $\begin{array}{l}\text { Ação de espíritos } \\
\text { desencarnados }\end{array}$ \\
\hline Bernardo & & $\begin{array}{l}\text { Sonho muito real; Confundido com } \\
\text { experiência vivida em vigília }\end{array}$ & $\begin{array}{l}\text { Sonho premonitório; PC } \\
\text { envolvendo mudanças climáticas }\end{array}$ & Coincidência \\
\hline Lurdes & \multirow{3}{*}{$\begin{array}{l}\text { III- Experiências } \\
\text { religiosas }\end{array}$} & Experiência de possível incorporação & $\begin{array}{l}\text { Sonho premonitório; Intuição; } \\
\text { Contato não natural }{ }^{1} \text {; PC } \\
\text { envolvendo mudanças climáticas }\end{array}$ & $\begin{array}{c}\text { Mensagem do Anjo da Guarda; } \\
\text { Mensagem ou ação de espíritos } \\
\text { desencarnados; Ação de Deus }\end{array}$ \\
\hline Alberto & & $\begin{array}{l}\text { Sonho com possível lembrança } \\
\text { de vida passada }\end{array}$ & - & - \\
\hline José & & $\begin{array}{l}\text { Incorporação que presenciou } \\
\text { em culto de Umbanda }\end{array}$ & Sonho premonitório & $\begin{array}{l}\text { Mensagem do Anjo da } \\
\text { Guarda; Mensagem de um } \\
\text { santo protetor; Mensagem de } \\
\text { espíritos desencarnados }\end{array}$ \\
\hline Priscila & \multirow{3}{*}{$\begin{array}{l}\text { IV-Sem } \\
\text { lembrança }\end{array}$} & - & 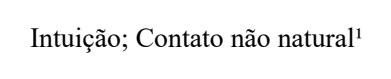 & $\begin{array}{l}\text { Mensagem de Deus; Ação de } \\
\text { espíritos desencarnados }\end{array}$ \\
\hline Renato & & - & - & - \\
\hline Mariana & & - & 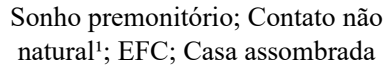 & $\begin{array}{l}\text { Poder da mente; Ação de } \\
\text { espíritos desencarnados; }\end{array}$ \\
\hline
\end{tabular}

'Experiência não natural: “Alguma vez, enquanto estava acordado (a), você já teve a nítida impressão de ver, ouvir ou ser tocado por alguém ou alguma coisa, sendo que essa impressão não parecia ser devida a nenhuma causa externa física ou 'natural'? (Por favor, não inclua aqui experiências com figuras religiosas.)"

Ai, nitidamente, acabou o sonho. Tipo, eu estava... acordado. Só que não acordado do jeito clássico, do jeito normal. Simplesmente eu tomei consciência do mundo externo. Mas sem usar o sentido, acho que... os sentidos normais. Sem ver, sem sentir cheiro... O tato tava muito aflorado, a audição tava... mais interna. Não tava pra fora, né? Tava pra dentro do meu corpo. (Raul)

Raul destaca a hipersensibilidade que a experiência produzira e que podia "sentir muito" seu próprio corpo. Contudo, sentia como se houvesse um segundo corpo colado ao seu corpo físico, "mas não separados fisicamente, (...) um deslocamento de corpo (...) contíguo ao corpo padrão" (Raul).

Diego e Raul acreditam que suas experiências foram próximas a uma EFC, mas que não há evidências ou sensação de realidade suficiente para confirmar tal fenômeno, de modo que entendem suas experiências como sonhos. Ana, embora não considere sua experiência como EFC, mostra-se relativamente propensa a entender suas experiências como tal. Contudo, na dúvida de se sua experiência se enquadra a uma EFC e por medo de ser iludida com sua própria imaginação, prefere rotular a experiência de modo mais material e racional, como descreve por si mesma:

Talvez nomear a experiência seja uma ação mais dessa... desse mundo material [risos]. Não sei, é uma coisa da relação material... Na minha relação comigo mesma, eu sinto muito as coisas, eu vou bastante pela intuição, pela abstração. Só que na hora de você nomear, parece que já é uma coisa mais... material. (Ana)

É curioso que, embora Ana e Diego neguem a existência de EFC em suas experiências relatadas, assinalaram positivamente a questão referente à EFC no questionário. Assim, ambos denotam uma diferença entre a sensação de exteriorização do lócus de percepção que relatam ter 
vivenciado e a $\mathrm{EFC}$, devido às suas dúvidas quanto à realidade da experiência que tiveram.

Dentre os três entrevistados, Ana é a única que alega mudanças em sua vida devido à experiência narrada, relatando redução de ansiedade e melhora em suas habilidades sociais ao começar a dar mais atenção às questões relacionadas à sua alma. Também é a única do grupo que se considera religiosa e acredita que a alma pode ser relacionada tanto com uma função psíquica quanto espiritual. Já Diego e Raul, ateus, se consideram nada religiosos e não acreditam em uma alma espiritual, entendendo alma como sinônimo de mente e diferente de espírito. Entretanto, todos afirmam já terem buscado auxílio de médium ou "paranormal".

No questionário aplicado, os três entrevistados assinalaram ter dúvida quanto à existência ou não de PES. Diego e Raul acreditam que possa existir, mas também consideram que tais experiências possam ser fruto de autossugestão, falha de percepção, erro de interpretação de eventos normais, imaginação ou, ainda, ser uma percepção mais sutil, mas ainda sensorial e material. Assim, não consideram que tais experiências sejam necessariamente mediúnicas, místicas ou transcendentais.

Os três entrevistados gostam de dialogar sobre EAs com amigos e familiares. Raul e Diego afirmam que as experiências descritas na entrevista e questionário não influenciaram suas crenças e visões de mundo, mas o segundo diz que estas o influenciaram na melhora de sua saúde e em escolhas como curso a estudar e mudanças de hábitos alimentares. Já Ana passou a estudar sobre tais experiências após vivenciá-las e diz que: os fenômenos anômalos que vivenciou influenciaram seu estilo de vida (ideias, propósitos ou objetivos de vida); tornaram-na mais observadora e reflexiva; influenciaram ou mudaram significativamente algum de seus sentidos ou atitudes em relação à vida, natureza, sociedade, família, estudos, trabalho, amor, ódio e medo da morte.

\section{Grupo II - Sonhos Lúcidos ou Muito Reais}

Quatro entrevistados descrevem experiências com sonhos vívidos e muito reais ou ainda sonhos lúcidos. Augusto (entrevista \#08) teve um sonho lúcido após realizar práticas de indução a tais sonhos por algum tempo. Afirma que, ao perceber que estava consciente e podia controlar suas ações no sonho, decidiu tentar voar, mas acordou assustado após algum tempo de voo.

Vanessa (entrevista \#10) também relata experiências de sonhos lúcidos, mas acompanhados de paralisia do sono e autoscopia. Em suas palavras:

Frequentemente quando durmo, eu sei que é um sonho, mas não consigo me mexer (...). Então, de alguma forma, eu vejo meu corpo na cama imóvel e isso me assusta porque eu não consigo sair daquela posição e pra que eu acorde eu tenho que fazer muita força. Então eu acordo levantando, porque eu fiz muita força pra sair do sonho. Mas eu não entendo, talvez, como um processo fora do corpo porque... pra mim é um sonho (...). É como se eu... estivesse sabendo que aquilo tá acontecendo, quando eu olho, falo: ai, não to conseguindo me mexer, to sonhando, preciso acordar. Ai eu faço força e acordo. (Vanessa)

Bernardo (entrevista \#06) e Karen (entrevista \#02) narram sonhos muito reais, os quais cogitaram que tivessem, de fato, ocorrido, mas que depois refutaram. As experiências de Augusto, Bernardo e Karen, embora com grande realismo e lucidez, não apresentam qualquer sinal de separação ou diferenciação com o corpo físico. Contudo, embora negue ter vivenciado qualquer EFC durante a entrevista, em seu questionário, Augusto assinala positivamente a referida questão.

A experiência narrada por Vanessa destaca-se pela presença de paralisia noturna e autoscopia, fenômenos muitas vezes concomitantes a experiências fora do corpo (Holt et al., 2012). Entretanto, assim como Diego e Raul (grupo I), Vanessa acredita que sua experiência careça de evidências ou realidade suficiente para considerá-la uma EFC. Ademais, embora tenha autoscopia, Vanessa não relata uma sensação de saída do corpo físico, de modo que a autoscopia ocorria de maneira abrupta, quando fazia força para acordar.

Augusto, Bernardo e Vanessa consideram a alma um processo da mente, um epifenômeno do cérebro, assim como Raul e Diego (grupo I). Karen, católica, tem uma visão de alma entre psíquica e espiritual, semelhante à de Ana (grupo I). Contudo, para Karen, essa diferenciação só ocorre após a morte, não conseguindo entendê-la durante a vida.

Karen é a única entrevista do grupo que acredita em PES. Os demais, assim como os entrevistados do grupo I, têm dúvidas com relação à existência de tais fenômenos, não sabendo se podem ou não existir realmente. Karen e Vanessa já procuraram auxílio de médium ou "paranormal", enquanto Bernardo e Augusto nunca o fizeram.

Em relação às EAs assinaladas pelos entrevistados (Quadro 1), Karina e Bruno afirmam que tais experiências em nada mudaram suas vidas ou crenças. André, por sua vez, diz que as experiências vividas fizeram com que mudasse sua atitude com as pessoas e que passou a estudar mais para entender tais experiências, porém, diz que estas não produziram qualquer mudança em sua crença religiosa ou visão de mundo.

\section{Grupo III - Experiências Religiosas}

Três outros entrevistados apresentam um entendimento de EFC com associação a conteúdos religiosos. José (entrevista \#13) diz que a experiência mais parecida à EFC foram suas visitas a um centro de Umbanda, pois entende que "o inverso da experiência fora do corpo seria uma alma se conectando com a sua". Da mesma maneira, Lurdes 
(entrevista \#05) relata uma suposta incorporação que teve durante a infância e Alberto (entrevista \#11) uma possível lembrança de vida passada, ocorrida durante um sonho.

Lurdes tem bastante interesse por tais experiências. Simpatizante do espiritismo, ela é católica e tem um pouco de medo de experiências espirituais e, assim, opta por entender suas próprias experiências como meros sonhos, mas confessa que se não fosse o medo, poderia considerar alguma EFC. Alberto é espírita e afirma que chegou a acreditar que teve uma lembrança de vida passada, mas, ao acordar, reconheceu a experiência como um pesadelo, pois comumente tem pesadelos quando está com frio, como no dia da experiência narrada. Esses três entrevistados são os únicos a apresentarem um entendimento de alma como essência imaterial que sobreviveria a morte, preservaria sua unidade e identidade ou, como para José e Alberto, animaria um novo corpo. Lurdes, por sua vez, diz que acredita um pouco no espiritismo, mas que é católica e isso a impede de acreditar em alguns conceitos espíritas, como a reencarnação.

Também são esses três entrevistados, juntamente com Ana, os únicos sujeitos a considerarem que as percepções extrassensoriais e as EFCs estão relacionadas a fenômenos mediúnicos. Todos os demais entrevistados se dividem entre o entendimento de que tais percepções são físicas, porém mais sutis, e a negação da possibilidade de tais eventos.

José é o único entrevistado deste grupo que tem dúvidas quanto à existência de PES, enquanto Lurdes e Alberto acreditam em sua existência. José também é único do grupo que nunca buscou auxílio com médium ou "paranormal".

Com relação às EAs (Quadro 1), José afirma que estas o influenciaram a mudar sua crença religiosa (adotou uma religião, passou a acreditar mais em Deus e a fazer mais orações), bem como, em sua escolha de amigos e em seus sentimentos ou atitudes em relação a si mesmo, suas emoções, sua visão da natureza humana e o medo da morte.
Lurdes diz que tem medo das experiências que viveu, mas relata mudanças em sua crença religiosa (deixou de ter uma religião específica e passou a frequentar cultos de religiões diferentes, a fazer mais orações e acreditar mais em Deus, praticar caridade e ser mais supersticiosa). Diz ainda que passou a estudar para entender estas experiências e que estas a influenciaram na escolha de amigos, com quem deveria se casar ou se divorciar, na decisão de engravidar, no nome a dar ao filho, em mudanças na dieta e hábitos alimentares e em seus sentimentos ou atitudes em relação a si mesma, suas emoções, família, visão da natureza humana, significado e propósito de sua vida, riquezas materiais e medo da morte.

\section{Grupo IV - Sem Lembrança de Experiência Específica}

Os três entrevistados restantes (entrevistas \#03, \#07 e \#12), não conseguindo relatar uma experiência similar, relataram fragmentos de sonhos ou mesmo questões genéricas sobre sua relação com os sonhos. Todos apresentaram uma crença em alma espiritual apenas após a morte, mas sem separação durante a vida.

Priscila (entrevista \#12) diz que tem medo de EAs e não gosta de falar ou pensar muito a respeito, mas afirma que as EAs que teve provocaram uma mudança em sua crença religiosa, fizeram-na acreditar mais em Deus e influenciaram seu estilo de vida, ideias e sentimentos e atitudes em relação a suas emoções. Mariana (entrevista \#07) diz que, por causa de suas experiências, passou a fazer mais orações, confirmou sua crença e mudou sua relação ou atitude para com as pessoas. Ela ainda relata que as experiências que relata no questionário influenciaram seus sentimentos ou atitudes em relação consigo, suas emoções, família e amigos, riquezas materiais e reputação.

\section{DISCUSSÃO}

Embora durante a entrevista nenhum participante tenha afirmado vivenciar uma EFC, os dados de seus relatos podem oferecer algumas contribuições para a discussão sobre sua definição. Dos quatro entrevistados que assinalaram positivamente a questão referente à EFC no questionário, dois (Augusto e Mariana) entrevistados não descrevem, durante a entrevista, experiências em que exista exteriorização do lócus de percepção. Assim, como apontado por Alvarado (2000), a prevalência de EFC indicada por meio de uso de questionário pode sofrer uma queda em função de uma maior exploração a respeito das experiências vividas. Contudo, os outros dois entrevistados (Ana e Diego) confirmam a existência de exteriorização do lócus de percepção nas experiências narradas durante a entrevista. Assim, embora não considerem a experiência vivida como uma EFC, não há dados para considerar tais casos como falsos positivos.

A experiência visual de saída do corpo de Diego se enquadra perfeitamente na descrição mais restrita dada por Alvarado (2000), na qual a exteriorização do lócus de percepção é fundamental. Já na experiência narrada por Ana, embora haja exteriorização do lócus de percepção, ela ainda se sente também em seu corpo físico, como nas experiências separativas dentro e fora do corpo descritas por Whiteman (1980, 2006). Embora a experiência de Ana não se enquadre a definição mais estrita de EFC, já que não há uma completa exteriorização do lócus de percepção, esta se enquadra em definições mais amplas, como a de Neppe (2011), que inclui experiências separativas ainda no corpo e dentro e fora do corpo. Do mesmo modo, a experiência de Raul, que não respondeu positivamente à questão de exteriorização do 
lócus de percepção (no questionário), também se enquadraria às EFCs como experiência separativa ainda dentro do corpo (Whiteman, 1980; 2006), devido à separação entre seu lócus de percepção e percepção de seu corpo físico que, naquele momento, eram percebidos como dois corpos.

O fato destas três experiências não serem consideradas EFC por aqueles que as vivenciaram corrobora a afirmativa de insuficiência causada por uma única questão para definir EFC, como apontado por Alvarado (2000), pois confirma a necessidade de separação entre a existência da experiência anômala e suas atribuições de causalidade (paranormais ou normais), sugerida por Irwin, Dagnall e Drinkwater (2013).

A separação entre a definição da experiência anômala e a atribuição de causalidade da experiência permitiria não só a inclusão como também a diferenciação dessas experiências sem atribuição paranormal com as EFCs com tal atribuição, assim como a diferenciação dessas duas com as experiências anômalas subjetivas (Neppe, 2011), as quais podem não se enquadrar como EFC, mas são entendidas como tal por aqueles que vivenciam, sendo classificadas como um subtipo de EFC, por seu caráter psíquico e subjetivo.

Embora os três entrevistados do grupo I (Ana, Diego e Raul) não considerem a experiência como uma real saída do corpo, descartando uma atribuição paranormal, pode-se observar algumas diferenças em suas experiências, no que tange à atribuição de causalidade e mudanças após a experiência. Ana é a única que levanta a possiblidade de ter, de fato, vivenciado uma EFC. É também a única de seu grupo que descreve mudanças significativas em sua vida após a experiência. Embora Ana opte por não definir sua experiência como EFC, o fato de levantar esta possibilidade, bem como atribuir tal fato à ação de seu espírito, parece estar relacionado com as mudanças impactadas pela experiência.

A relação entre mudanças na vida e crença dos sujeitos após uma EFC e atribuição paranormal pode ser observada na comparação entre o estudo de Osis (1979) e Blackmore (1984b). Enquanto 95\% dos participantes da pesquisa de Osis (1979) relatam mudanças na vida ou crença após a EFC (e apenas 4\% relacionam sua experiência com imagens oníricas, ao passo que os demais utilizam explicações paranormais), no estudo de Blackmore (1984b), apenas $10 \%$ relatam alguma mudança na vida após a EFC (e 50\% de toda a amostra relaciona sua EFC com imagens oníricas). Assim, Diego e Raul, que entendem suas experiências como uma ilusão da percepção, semelhantemente aos dados de Blackmore (1984b), não apresentam mudanças em suas vidas, em decorrência da experiência narrada.

Ana e Karen são as únicas entrevistadas dos grupos I (Quasi-EFC) e II (Sonhos vívidos e muito reais), respectivamente, que consideram a possibilidade de existência de uma alma espiritual. Elas também são as únicas nestes grupos que atribuem causas paranormais a suas EAs, confirmando a relação entre crença paranormal e atribuição paranormal (Irwin et al., 2013). Assim, se assemelham à postura paranormófila dos entrevistados dos grupos III e IV (exceto Renato), que também acreditam em alma espiritual e PES e apresentam atribuições paranormais às suas EAs (Machado, 2010, p. 477).

Estudos relacionam uma pontuação mais elevada em crença paranormal com diversos fatores psicológicos. Entre estes, alguns foram considerados fortes preditores de crença paranormal, como: preferência pelo pensamento experiencial e emocional em detrimento do racional (Irwin et al., 2013; Vasconcellos \& Trócoli, 2004); baixa inclinação a reavaliações rigorosas a respeito de eventos, frente a novas informações relevantes (Irwin et al., 2013); absorção (tendência a focalizar grande parte da atenção consciente no que está sendo imaginado, em detrimento de outros aspectos da realidade) e propensão à fantasia (Maraldi et al., 2011). Irwin et al. (2013) ainda apontam que o apelo intuitivo de atribuições paranormais tende a aumentar com o aumento do número de EAs vividas. Isso ocorre porque, segundo o estudo, tais indivíduos aprendem a direcionar suas atenções e memórias para EAs, inferir relações causais e padrões em experiências ambíguas e práticas que induzem ou aumentam a chance de ter EAs. Assim, os autores sugerem que as EAs estejam em um ciclo de feedback com suas atribuições paranormais, no qual uma alta incidência de atribuições paranormais pode resultar em um alto número de EAs e experiências ambíguas consideradas EAs, bem como uma alta incidência de EAs pode resultar em maior número de atribuições paranormais.

Contudo, em nosso estudo, os únicos que afirmam ter feito práticas para induzir EAs (sonhos lúcidos) foram Raul e Augusto, os quais atribuem causas psicológicas para suas EAs. Já entre os entrevistados com postura paranormófila, apenas Ana (Grupo I), Lurdes (Grupo III) e Mariana (Grupo IV) apresentam uma quantidade maior de tipos de EAs vividas. Os demais entrevistados assinalaram uma quantidade muito semelhante de EAs, a despeito de suas crenças e atribuições paranormais ou não. Outros entrevistados com postura paranormófila, embora tenham crença paranormal, apresentam em seus discursos ceticismo e medo de fantasiar. É o caso de Alberto, que embora tenha inicialmente acreditado que sua experiência fosse uma lembrança de vida passada, opta por concluir que fora apenas um sonho. Assim, embora a crença paranormal tenha grande influência na atribuição de causalidade de experiências ambíguas, a capacidade de tornar-se convicto de sua experiência (Blackmore, 1984a) é mais importante do que a vivacidade da experiência.

Os dados apresentados também sugerem uma relação entre crença paranormal e religiosa. Os entrevistados com postura paranormófila foram, em geral, os que afirmaram ter filiação religiosa e relataram mudanças na crença religiosa após as EAs assinaladas no questionário. Estes também acreditam na existência de uma alma espiritual (diferente da mente) e entendem EFC e PES como dons mediúnicos. A relação com EAs e mediunidade também é encontrada em Machado (2010), em que 32,4\% dos entrevistados com EAs 
entendem-nas como um dom especial e 47,4\% consideram tais experiências como provas da existência de um mundo espiritual. Assim, a relação entre crença religiosa e atribuição paranormal ou espiritual é mais acentuada em religiões mediúnicas e movimentos espiritualistas devido à crença paranormal e espiritual dos participantes ser reforçada; aos participantes serem mais propensos à EAs, através das práticas religiosas (Irwin et al., 2013), e à sensação de controle ser intensificada pelas explicações oferecidas, suprindo uma lacuna de significação (Machado, 2010). Desse modo, Lurdes, católica e "espírita simpatizante", relata ter medo das EAs que viveu; Priscila e Renato, também católicos, dizem não ter interesse pelo tema de experiências anômalas.

\section{CONCLUSÃO}

Dos treze entrevistados que afirmaram não ter vivido uma EFC, um entrevistado narra uma experiência que se enquadra perfeitamente na definição mais restrita de EFC. Dois deles narram experiências que também podem ser consideradas EFC, em definições mais amplas (Neppe, 2011). Essas experiências não apenas se diferem pelos elementos presentes, mas também pelo sentido dado a elas e seu papel e consequências na vida do sujeito. Embora nenhum dos entrevistados entenda que viveu uma EFC, o fato de considerar a possibilidade, aliado a uma crença paranormal e espiritual, pareceram poder afetar o sentido da experiência, bem como seu papel e consequências na vida daqueles que a vivenciam. Ademais, parece-nos que o entendimento de EFC para tais sujeitos está intimamente vinculado à atribuição paranormal.

Assim, os dados apresentados reforçam que o uso de apenas uma questão para identificação de EFC seja insuficiente (Alvarado, 2000) e apontam para a necessidade de separação entre a experiência anômala de exteriorização do lócus de percepção e a atribuição de causalidade.

Por fim, mesmo que se trate de um fenômeno de múltiplas abordagens, com variadas explicações etiológicas e características diversas, o uso de uma perspectiva multietiológica e fenomenológica permitiria comparar EFCs semelhantes com semelhantes, de modo a entender tipos específicos de experiência. Tal perspectiva auxiliaria o estudo em Parapsicologia, Psicologia Anomalística, Psiquiatria e pesquisadores da consciência a obterem informações mais profundas e precisas sobre a observação de grupos de experiências homogêneas (Neppe, 2011). Ademais, pode melhor elucidar o papel da crença paranormal e religiosa, bem como o papel da experiência na vida do sujeito, por meio de comparação nos grupos homogêneos e entre as diferentes categorias de EFC.

\section{REFERÊNCIAS}

Alvarado, C. S. (1989). Trends in the study of out-of-body experiences: An overview of developments since the nineteenth century. Journal of Scientific Exploration, 3(1), 27-42.

Alvarado, C. S. (2000). Out-of-body experiences. In E. Cardeña, S. J. Lynn, \& S. Krippner (Org.), Varieties of anomalous experience: Examining the scientific evidence (pp. 183-218). Washington, DC: American Psychological Association.

Alvarado, C. S. (2016). Out-of-body experiences during physical activity: Report of four new cases. Journal of the Society for Psychical Research, 80, 1-12.

Blackmore, S. J. (1982). Beyond the body: An investigation of outof-the-body experiences. London: Heinemann.

Blackmore, S. J. (1984a). A psychological theory of the out-of-body experience. Journal of Parapsychology, 48, 201-218.

Blackmore, S. J. (1984b). A postal survey of OBEs and other experiences. Journal of the Society for Psychical Research, 52(796), 225-244.

Blackmore, S. J. (1986). Spontaneous and deliberate OBEs: A questionnaire survey. Journal of the Society for Psychical Research, 53, 218-224.

Blackmore, S. J. (1987). Where am I? Perspectives in imagery and the out-of- body experience. Journal of Mental Imagery, 11, 53-66.

Blanke, O., \& Arzy, S. (2005). The out-of-body experience: Disturbed self- processing at the temporo-parietal junction. Neuroscientist, 11(1), 16-24.
Blanke, O., Landis, T., Spinelli, L., \& Seeck, M. (2004). Out-ofbody experience and autoscopy of neurological origin. Brain, 127(2), 243-258.

Blanke, O., Ortigue, S., Landis, T., \& Seeck, M. (2002). Stimulating illusory own-body perceptions. Nature, 419(6904), 269-270.

Bozzano, E. (1911). Considerations et hypothèse sur les phénomènes de bilocation. Annales des Sciences Psychiques, 21, 65-72, 109-116, 143-154 e 166-172.

Cardeña, E., Lynn, S. J., \& Krippner, S. (2000). Varieties of anomalous experience: Examining the scientific evidence. Washington DC: American Psychological Association.

Creswell, J. W. (2012). Qualitative inquiry and research design: Choosing among the five traditions (3a ed.). Thousand Oaks, CA: Sage.

De Ridder, D., Van Laere, K., Dupont, P., Menovsky, T., \& Van De Heyning P. (2007). Visualizing out-of-body experience in the brain. New England Journal of Medicine, 357(18), 1829-1833.

Ehrsson, H. H. (2007). The experimental induction of out-of-body experiences. Science, 317(5841), 1048.

Freitas, M. H., Araújo, R. C., Franca, F. S. L., Pereira, O. P., \& Martins, F. (2012). Os sentidos do sentido: Uma leitura fenomenológica. Revista da Abordagem Gestáltica, 18(2), 144-154.

Gabbard, G. O., \& Twemlow, A. W. (1984). With the eyes of the mind: An empirical analysis of out-of-body states. New York: Praeger Scientific. 
Green, C.E. (1966). Spontaneous 'paranormal' experiences in relation to sex and academic background. Journal of the Society for Psychical Research, 43, 357-363.

Haraldsson, E., Gudmundsdottir, A., Ragnarsson, A., Loftsson, J., \& Jonsson, S. (1977). National survey of psychical experiences and attitudes towards the paranormal in Iceland. In J. D. Morris, W. G. Roll, \& R. L. Morris (Eds.), Research in Parapsychology (182-186). Metuchen, N.J.: Scarecrow Press.

Hart, H. (1954). ESP projection: Spontaneous cases and the experimental method. Journal of the American Society for Psychical Research, 48, 121-146.

Holt, N. J., Simmonds-Moore, C., Luke, D., \& French, C. C. (2012). Anomalistic Psychology. London: Palgrave Macmillan.

Irwin, H. J. (1985). Flight of mind: A psychological study of the out-of-body experience. Metuchen, New Jersey: The Scarecrow Press.

Irwin, H. J., Dagnall, N., \& Drinkwater, K. (2013). Parapsychological experiences as anomalous experience plus paranormal attribution: A questionnaire based on a new approach to measurement. Journal of Parapsychology, 77, 39-53.

Kohr, R. L. (1980). A survey of psi experiences among members of a special population. Journal of the American Society for Psychical Research, 74, 395-411.

LaBerge, S., Levitan, L., Brylowski, A., \& Dement, W. (1988). "Out-of-body" experiences occurring during REM sleep. Sleep Research, 17(115).

LaBerge, S., Nagel, L., Dement, W. C., \& Zarcone, V. (1981). Lucid dream verified by volitional communication during REM sleep. Perceptual \& Motor Skills, 52, 727-32.

Levitan, L., LaBerge, S., DeGarcia, D. J., \& Zimbardo, P. G. (1999). Out-of-body experiences, dreams, and REM sleep. Sleep and Hypnosis, 1(3), 186-96.

Maraldi, E. O., Zangari, W., \& Machado, F. R. (2011). A Psicologia das crenças paranormais: uma revisão crítica. Boletim Academia Paulista de Psicologia, 31, 394-421.

Machado, F. R. (2009). Experiências anômalas na vida cotidiana: Experiências extra-sensório- motoras e sua associação com crenças, atitudes e bem-estar subjetivo (Tese de Doutorado). Instituto de Psicologia, Universidade de São Paulo, São Paulo, SP, Brasil.

Machado, F. R. (2010). Experiências anômalas (extra-sensóriomotoras) na vida cotidiana e sua associação com crenças, atitudes e bem-estar subjetivo. Boletim - Academia Paulista de Psicologia, 30, 462-483.

Merleau-Ponty, M. (2006). Fenomenologia da percepção (3. ed., trad. Moura, C. A. R.). São Paulo: Editora Martins Fontes.

Mota-Rolim, S. A., \& Araujo, J. F. (2013). Neurobiology and clinical implications of lucid dreaming. Medical Hypothesis 81, 751-756.

Mota-Rolim, S. A., Targino, Z. H., Souza, B. C., Blanco, W., Araujo, J. F., \& Ribeiro, S. (2013). Dream characteristics in a Brazilian sample: an online survey focusing on lucid dreaming. Frontiers in Human Neuroscience, 7(836).

Moustakas, C. (1994). Phenomenological research methods. Thousand Oaks, CA: Sage.

Myers, F. W. H. (1903). Human personality and its survival of bodily death (2 Vols.). London: Longmans, Green.

Neppe, V. M. (1989). Near-death experiences: A new challenge in Temporal Lobe phenomenology? Comments on "A neurobiological model for near-death experiences". Journal of Near-Death Studies, 7(4), 243-8.

Neppe, V. M. (2011). Models of the out-of-body experience: A new multi-etiological phenomenological approach. NeuroQuantology, 9(1), 72-83.
Osis, K. (1973). Perspectives for out of body research. In W. G. Roll (Ed.), Research in Parapsychology. Metuchen, NJ, Scarecrow Press.

Osis, K. (1979). Insider's view of the OBE: A questionnaire study. In W. G. Roll (Ed.), Research in parapsychology (pp. 50-52). Metuchen, NJ: Scarecrow Press.

Palmer, J. (1978). The out-of-body experience: A psychological theory. Parapsychology Review, [S.l.], 9(5), 19-22.

Palmer, J. (1979). A community mail survey of psychic experiences. Journal of the American Society for Psychical Research, 73, 221-251.

Palmer, J., \& Lieberman, R. (1975). The influence of psychological set on ESP and out-of-body experiences. Journal of the American Society for Psychical Research, 69, 193-214.

Palmer, J., \& Lieberman, R. (1976). ESP and out-of-body experiences: A further study. In J. D. Morris, W. G. Roll, \& R. L. Morris (Ed.), Research in parapsychology (pp. 102-106). Metuchen, NJ: Scarecrow Press.

Palmer, J., \& Vassar, C. (1974). ESP and out-of-the-body experiences: An exploratory study. Journal of the American Society for Psychical Research, 68, 257-80.

Patton, M. Q. (1990). Qualitative evaluation and research methods. Newbury Park: Sage.

Persinger, M. A. (1989). Invited address. In Research in Parapsychology. Metuchen, NJ: Scarecrow Press.

Sadala, M. L. A. (2004). A fenomenologia como método para investigar a experiência vivida: uma perspectiva do pensamento de Husserl e de Merleau-Ponty. Anais do Seminário Internacional de Pesquisa e Estudos Qualitativos, 2, cd- rom.

Sá, J. F. R., \& Mota-Rolim, S. A. (2015). Experiências fora do corpo: Aspectos históricos e neurocientíficos. Ciências \& Cognição, 20(1), 189-198.

Tart, C. T. (1968). A psychophysiological study of out-of-body experiences in a selected subject. Journal of the American Society for Psychical Research, 62, 3-27.

Tart, C. T. (1972). States of Consciousness and State-Specific Sciences. Science, [S.l.], 176, 1203-1210.

Tart, C. T. (1976). A second psychophysiological study of out-of-body experiences in a gifted subject. Journal of Parapsychology, 9, 251-258.

Tressoldi, P. E., Pederzoli, L., Caini, P., Ferrini, A., Melloni, S., Richeldi, D., ... Trabucco, A. (2014). Out of body experience induced by hypnotic suggestion. Part 1: Phenomenology and perceptual characteristics. SSRN Electronic Journal. doi: 10.2139/ssrn.2443719

Twemlow, S. W., Gabbard, G. O., \& Jones, F. C. (1982). The outof-body experiences: A phenomenological typology based on questionnaire responses. American Journal of Psychiatry, $139,450-455$.

Vasconcellos, T. S., \& Trócoli, B. T. (2004). Crenças no paranormal e estilos de pensamento racional versus experiencial. PsicoUSF, 9(2), 155-164.

Veríssimo, D. S., \& Furlan, R. (2007). Entre a filosofia e a ciência: Merleau-Ponty e a psicologia. Paideia, 17(38), 331-342.

Whiteman J. H. M. (1980). Separative experience. Psi, 2(1), 1-4.

Whiteman, J. H. M. (2006). Old and new evidence on the meaning of life (Vol. 3). Gerrards Cross: Colin Smythe.

Zangari, W., \& Machado, F. R. (2001). Incidência e relevância social de experiências Psi de estudantes universitários brasileiros. Revista Virtual de Pesquisa Psi. Recuperado de http://www.espiritualidades.com.br/Artigos/ Z autores/ ZANGARI Wellington e MACHADO Fatima Regina tit Incidencia_e_Relevancia_Social_das_Experiencias_Psi_de Estudantes_Universitarios_Brasileiros.htm 